(2) Open Access Full Text Article

\title{
Sequential occlusion of the branch retinal artery and branch retinal vein in a patient with hypertension: an interventional case report
}

This article was published in the following Dove Press journal:

Clinical Ophthalmology

17 October 2014

Number of times this article has been viewed

\section{Norio Okamoto \\ Chota Matsumoto \\ Yoshikazu Shimomura \\ Department of Ophthalmology, Kinki University Faculty of Medicine, Osakasayama City, Osaka, Japan}

Background: There are some cases that reported central retinal vein occlusion accompanied by ciliary artery occlusion, however, combined branch retinal artery and vein occlusion is a rare condition that has been infrequently reported. We describe in this report one case of retinal vein occlusion and branch retinal artery occlusion occurring simultaneously.

Case presentation: A 50 year-old woman presented with acute visual loss in her right eye. Fundus photography showed retinal ischemia and tortuous, dilated retinal veins in the right eye. With early phase fluorescein angiography, retinal arteries revealed areas absent of branches. Late phase fluorescein angiography demonstrated that areas absent of branches were still present. Conclusion: It is a rare case of branch retinal artery and vein occlusion.

Keywords: branch retinal artery occlusion, branch retinal vein occlusion, retinal vessel

\section{Background}

The pathophysiology of branch retinal vein occlusion (BRVO) consists of thrombosis caused by narrowing of the retinal vein at the arteriovenous crossing site and consequent retinal vein occlusion. When the retinal vein is obstructed, the blood pressure increases in the retinal vein distal to the site of occlusion, which eventually causes hemorrhage due to vascular breakdown.

On the other hand, branch retinal artery occlusion (BRAO) is a disorder that shows an occluded branch retinal artery because of thrombosis, emboli or some other causes. Consequently the blood flow to the retina will be suspended.

There are some case reports on central retinal vein occlusion accompanied by retinal artery occlusion, however, there are few reports on BRVO and BRAO occurring simultaneously in the same quadrant of the retina.

We observed a case in which BRAO and BRVO occurred at the same time because of hypertension.

\section{Case presentation}

A 50 year-old female noticed a sudden vision loss in her right eye. Decimal visual acuity was 0.2 in the right eye and 1.5 in the left eye. Intraocular pressure was $15 \mathrm{mmHg}$ in both eyes. Biomicroscopic examination of the anterior segment was unremarkable bilaterally. Fundus examination was unremarkable in the left eye. Fundus examination in the right eye revealed retinal ischemia and tortuous, dilated retinal veins in the supra temporal quadrant of the retina (Figure 1). Fluorescein angiography of the right eye showed significantly delayed filling of the branches of the superior retinal artery in
Correspondence: Norio Okamoto Department of Ophthalmology, Kinki University Faculty of Medicine, 377-2, Ohonohigashi, Osakasayama City, Osaka, 589-85II, Japan

$\mathrm{Tel}+8 \mid 72366022$ I

Fax +81723682559

Email eyedoctor9@gmail.com 


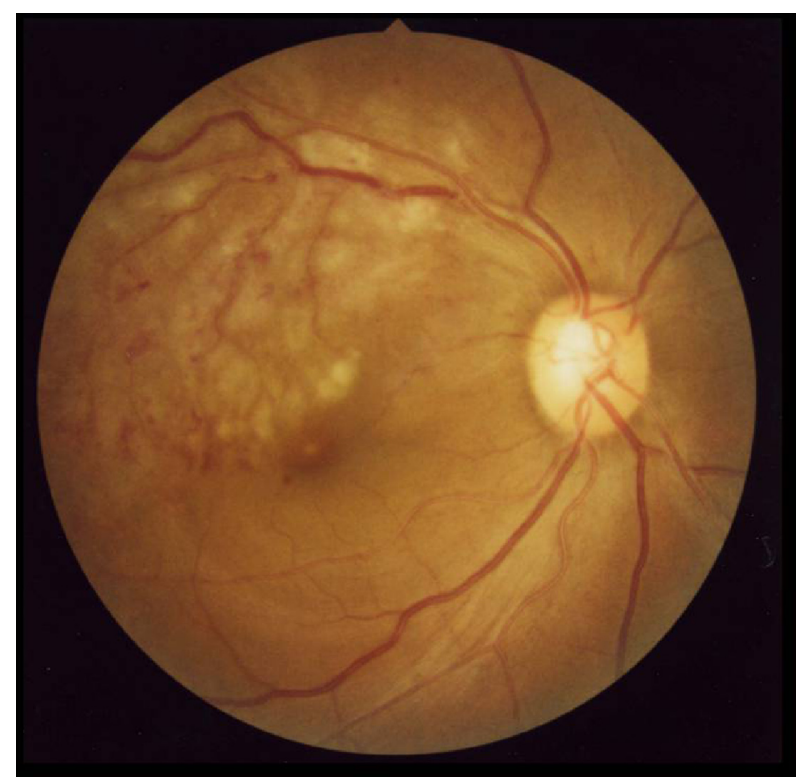

Figure I Fundus photo at the initial visit (right eye).

the ischemic area $(27.9 \mathrm{sec})$ (Figure 2$)$. The retinal vein was dilated and tortuous. The retinal artery exhibited sludging (70 sec) (Figure 3). Late phase examination revealed areas absent of branches (352.6 sec) (Figure 4). We diagnosed the case as BRAO combined with BRVO. Therefore, aspirin was prescribed one tablet/day. She had previously been diagnosed with hypertension but abandoned the treatment. Immediately, we consulted the Department of Internal Medicine of the university hospital, where her blood pressure was measured as $180 / 110 \mathrm{mmHg}$.

Amlodipine besilate was administered $5 \mathrm{mg} /$ day. Two weeks later, her right visual acuity had improved to 0.5 . One month after administration of amlodipine, her blood pressure did not recover to normal. Therefore, telmisartan

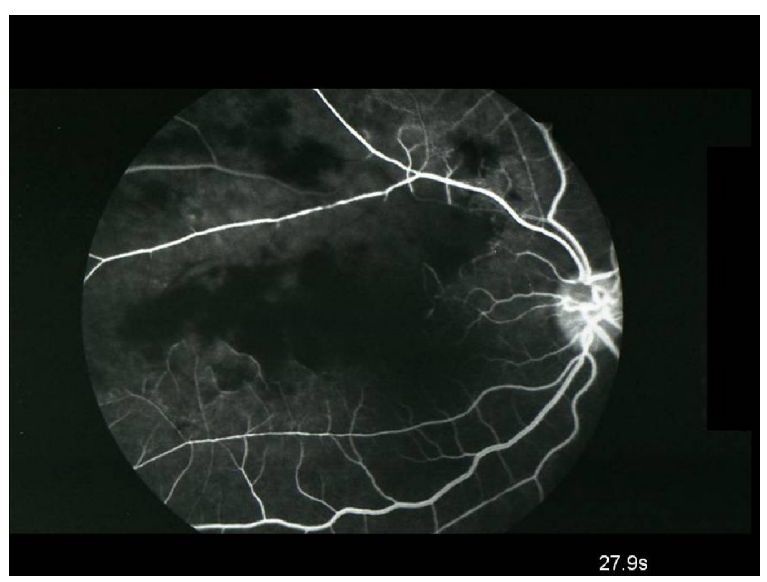

Figure 2 Fluorescein angiography of the right eye showed significantly delayed filling of the branches of the superior retinal artery in the ischemic area $(27.9 \mathrm{sec})$.

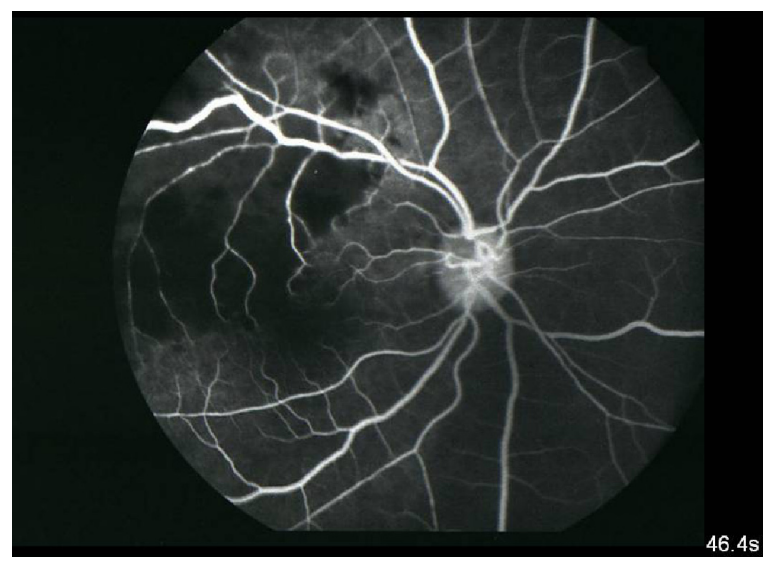

Figure 3 The retinal vein was dilated and tortuous.

Note: The retinal artery exhibited sludging $(46.4 \mathrm{sec})$.

was prescribed additionally for $40 \mathrm{mg} /$ day. Afterwards, fundus appearance was improved, and retinal opacity and retinal vessel abnormality disappeared. Nine months later, her visual acuity improved to 1.5 . Her blood pressure was 125/80 mmHg.

\section{Conclusion}

It is very rare that retinal artery occlusion and retinal vein occlusion occur simultaneously. In these cases of combined retinal artery and vein occlusion, the most frequent cases are central retinal vein occlusion accompanied by ciliary artery occlusion. ${ }^{1}$

The main fundus finding of this case was retinal opacity, therefore, BRAO could be suspected. However, we also saw dilated, tortuous retinal veins. Therefore, we diagnosed it as BRAO accompanied by BRVO. Usually BRAO has thrombosis in the retinal artery, however, this case did not exhibit thrombosis.

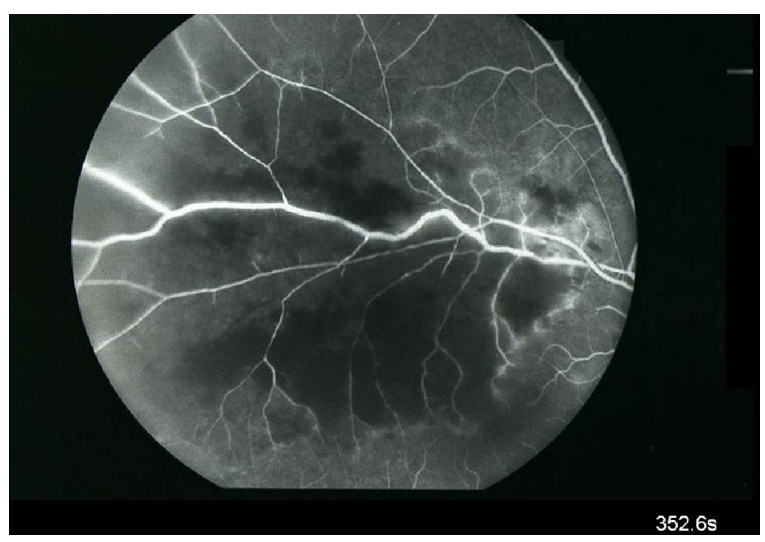

Figure $4 \mathrm{~A}$ capillary non-perfusion in the circulation of the supratemporal vein was also noticed.

Note: The retinal artery shows areas absent of branches still present $(352.6 \mathrm{sec})$. 


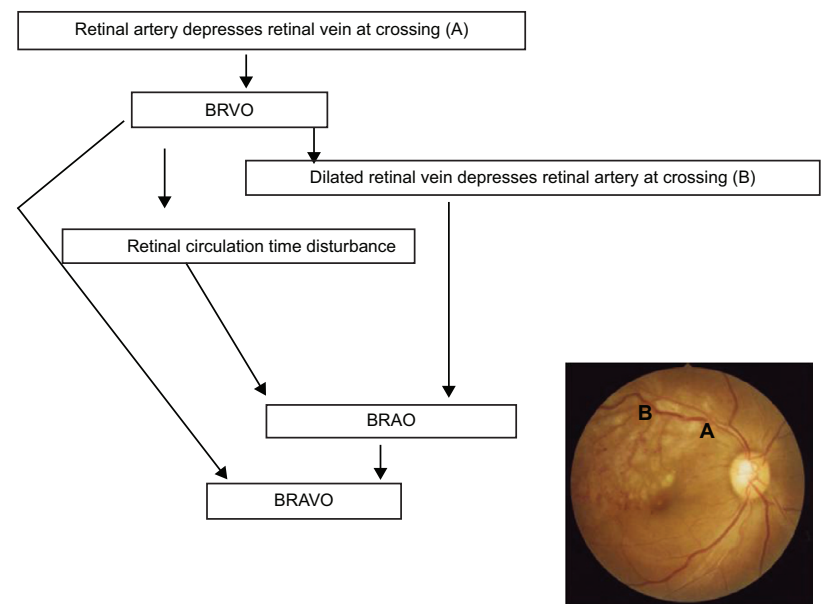

Figure 5 Suggested mechanism of BRAVO.

Notes: First, hypertension causes the retinal artery to compress the retinal vein at the crossing point, where the retinal artery crosses over the retinal vein (A). Next, the retinal vein becomes dilated and tortuous. Then, the dilated and tortuous retinal vein causes retinal circulation disturbance, which leads to elevated retinal vein pressure. As the retinal vein pressure is elevated, the retinal vein, in return, compresses the retinal artery at the reverse-crossing point, where the retinal vein crosses over the retinal artery (B), finally forming BRVO.

Abbreviations: BRVO, branch retinal vein occlusion; BRAO, branch retinal artery occlusion; BRAVO, branch retinal artery and vein occlusion.

There were three cases that reported branch retinal artery and vein occlusion (BRAVO) in the past: the first case occurred with a foreign object causing a laceration of the optic nerve and subsequent retinal vascular occlusions, ${ }^{2}$ the second case happened during hepatitis $\mathrm{C}$ treatment with interferon and ribavirin, ${ }^{3}$ and the third one presented with hypertension and type 2 diabetes mellitus. ${ }^{4}$

The case reported by An and Kwon resembles the present case. ${ }^{4}$ Compared to the present case, their case showed pale retinal artery indicating more severe occlusion and a higher degree of retinal opacity than our case. Their case did not show remarkable dilatation or tortuosity of retinal veins.
Fluorescein angiography revealed nonvascular areas and remarkable dye leakage. Their case showed severe retinal ischemia that should have triggered neovascular glaucoma. Our case did not develop neovascular glaucoma; we suggest that it was because the retinal ischemia improved at an early stage. We speculate that it might have followed the mechanism shown in Figure 5. First, hypertension probably causes compression of the retinal vein by the retinal artery at the crossing point, which, in return, causes retinal vein pressure to elevate (BRVO). Next, the elevated retinal vein pressure may cause the retinal vein to be dilated and tortuous. Then, the dilated and tortuous retinal vein, in return, compresses the retinal artery at the reverse-crossing point, where the vein crosses over the artery (BRAO). And finally BRAVO is formed.

\section{Acknowledgment}

Written informed consent was obtained from the patient for publication of this case report and any accompanying images.

\section{Disclosure}

The authors report no conflicts of interest in this work.

\section{References}

1. Hayreh SS, Fraterrigo L, Jonas J. Central retinal vein occlusion associated with cilioretinal artery occlusion. Retina. 2008;28(4):581-594.

2. Nicolo M, Artioli S, La Mattina GC, Ghiglione D, Calabria G. Branch retinal artery occlusion combined with branch retinal vein occlusion in a patient with hepatitis $\mathrm{C}$ treated with interferon and ribavirin. Eur J Ophthalmol. 2005;15(6):811-814.

3. Lee MW, Lee SY, Ong SG. Optic disc laceration with combined retinal artery and vein occlusion following penetrating injury. Clin Experiment Ophthalomol. 2007;35(5):486-490.

4. An TS, Kwon SI. Neovascular Glaucoma Due to Branch Retinal Vein Occlusion Combined with Branch Retinal Artery Occlusion. Korean J Ophthalmol. 2013;27(1):64-67.
Clinical Ophthalmology

\section{Publish your work in this journal}

Clinical Ophthalmology is an international, peer-reviewed journal covering all subspecialties within ophthalmology. Key topics include: Optometry; Visual science; Pharmacology and drug therapy in eye diseases; Basic Sciences; Primary and Secondary eye care; Patient Safety and Quality of Care Improvements. This journal is indexed on

\section{Dovepress}

PubMed Central and CAS, and is the official journal of The Society of Clinical Ophthalmology (SCO). The manuscript management system is completely online and includes a very quick and fair peer-review system, which is all easy to use. Visit http://www.dovepress.com/ testimonials.php to read real quotes from published authors. 